\title{
Does body and fin form affect the maneuverability of fish traversing vertical and horizontal slits?
}

\author{
Paul W. Webb, ${ }^{1}$ Gina D. LaLiberte ${ }^{2}$ \& Amy J. Schrank ${ }^{1}$ \\ ${ }^{1}$ Department of Biology and School of Natural Resources and Environment, University of Michigan, Ann \\ Arbor, MI 48109-1115, U.S.A. \\ ${ }^{2}$ Present address: Department of Biology, Bowling Green University, Bowling Green, PH 43403, U.S.A.
}

Received 14.12.1994

Accepted 3.7.1995

Key words: Goldfish, Angelfish, Silver dollar, Swimming, Maneuver

\section{Synopsis}

The purpose of this study was to determine if body and fin form affected the maneuverability of teleostean fishes as measured by their ability to negotiate simple obstacles. Obstacles were vertical and horizontal rectangular slits of different widths, for which width was defined as the minimum dimension of a slit irrespective of slit orientation. Performance was measured as the smallest slit width traversed. Three species with different body and fin patterns were induced to swim through slits. Species tested were; goldfish Carassius auratus with a fusiform body, anterio-ventral pectoral fins and posterio-ventral pelvic fins; silver dollars Metynnis hypsauchen with the same fin configurations but a gibbose body; angelfish Pterophyllum scalare with a gibbose body and anterio-lateral pectoral fins. Minimum slit widths negotiated were normalized with the length of various body dimensions: total length, maximum width, span at the pectoral fins, and volume ${ }^{1 / 3}$ (numerically equal to mass ${ }^{1 / 3}$ ). Goldfish had the poorest performance, requiring the largest slit widths relative to these body dimensions. No consistent patterns in performance were found for silver dollars vs. angelfish. There were no differences among species in the ratio of minimum vertical slit width negotiated to that for horizontal slits, indicating fish were equally able to control posture while swimming on their sides. There were also no consistent patterns in the times taken to transit slits. Although the deep-bodied fish were able to maneuver through smaller slits, the most striking result is the similarity of minimum slit widths traversed in spite of the large variation in body form. Body form and fin plan may be more important for maneuvering and posture control during sub-maximum routine activities.

\section{Introduction}

Many fish swim with ease in restricted spaces, an ability loosely termed maneuverability. Performance in maneuvers during translocation using the body and caudal fin propulsors is measured as minimum turning radius (Howland 1974, Norberg 1990, Webb 1994a), and has been shown to be affected by body and fin morphology (Howland 1974, Webb
1976, 1983, Webb \& Keyes 1981, Blake et al. 1995). However, pedestrian and neutrally buoyant animals can rotate, turning with zero radius without translocation, thereby further reducing the volume required when turning (Blake 1976, 1977, 1978). This latter high level of maneuverability is achieved by animals with diverse body forms, but always at low speed. For fish, these low speed maneuvers typ- 

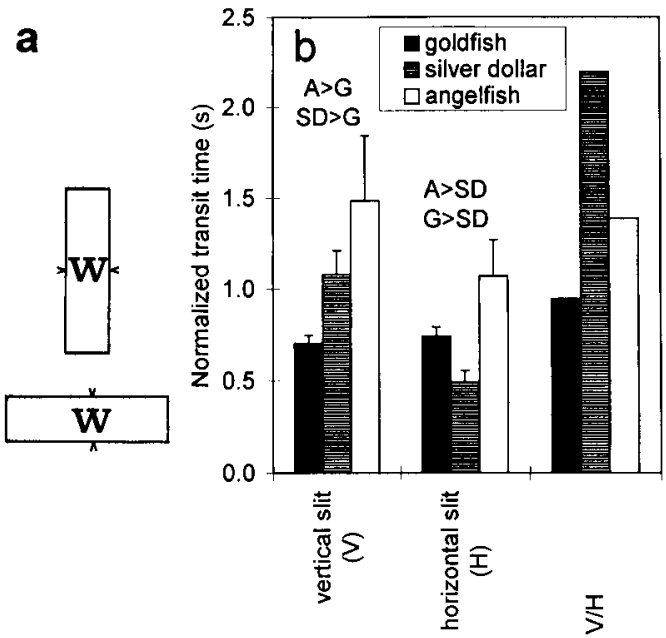

Fig. 1. a-Illustration of slit width, W, as the smallest dimension of a slit for both horizontal and vertical slits. $b$ - Normalized transit times through the narrowest traverable vertical, $\mathrm{V}$, and horizontal, H, slits for three species of teleosts, goldfish, G, silver dollars, $\mathrm{SD}$, and angelfish, A, with different body forms. The ratio, $\mathrm{V} / \mathrm{L}$, for normalized transit times is included to emphasize that longer times were used to traverse vertical slits. Rankings of significant differences are shown as determined in 2-tailed $t$-tests. Vertical bars show $2 \mathrm{SE}$.

ically involve propulsion with the median and paired fins.

Among fishes, a deep body and multiple propulsors arranged around the center of mass are believed to promote maneuverability (Breder 1926, Alexander 1967, Howland 1974, Webb 1983, 1984, 1994a, b, Ehlinger \& Wilson 1988, Ehlinger 1990). Following the precedent set by Breder of naming swimming patterns after exemplary groups plus the suffix 'form', these deep-bodied fish can be characterized as chaetodontiform, after the butterflyfishes in the family Chaetodontidae (Webb 1984). The superior maneuverability of chaetodontiform fishes is supported by a wealth of natural history observations (Moyle \& Cech 1988). However, experimental data are lacking.

Swimming by chaetodontiform fishes primarily involves the median and paired fins. Like many fishes, these propulsors are used during routine swimming, which is typically a low speed activity (Boisclair 1992, Boisclair \& Tang 1993, Krohn \& Boisclair 1994, Webb 1991, Nilsson et al. 1993).

We describe a simple experiment to test maneu- verability at low swimming speeds. Goldfish, silver dollars and angelfish were induced to swim through simple two-dimensional obstacles, vertical and horizontal slits. We expected more maneuverable species to be able to align themselves to traverse narrower slits. Therefore, our a priori expectation was that angelfish would traverse the smallest slit widths, goldfish the largest, with silver dollars being intermediate.

\section{Methods}

Goldfish Carassius auratus, silver dollars Metynnis hypsauchen and angelfish Pterophyllum scalare were obtained from pet stores. Each species was held in a separate aquarium maintained at $25^{\circ} \mathrm{C}$. Water was continuously aerated with a floss-filled air-lift corner filter in each tank.

Each tank was divided vertically by a removable opaque partition, $0.8 \mathrm{~mm}$ thick, held in a frame. Single vertical or horizontal slits were cut in partitions inserted in the frames. Partitions with a large vertical slit were left in place at all times, including two or more weeks before experiments began. Food was added to one side of the partition requiring fish to swim through slits to feed. Therefore, fish were accustomed to swimming through slits. Throughout the experiments, there was no evidence that fish gained experience, learning to swim through narrower slits as experiments progressed.

After conditioning fish to the experimental system, fish were induced to swim through slits of various widths. Width was defined as the smallest dimension of a slit, irrespective of orientation. Thus width was the vertical dimension of a horizontal slit and the horizontal dimension of a vertical slit (Fig. $1)$.

We found food, even for hungry fish, was an insufficient stimulus for determining the minimum slit width a fish could negotiate. Instead, the minimum slit width fish could traverse was determined by herding the fish towards the partition using a net or a paddle. Fish sought to escape this threat stimulus by swimming through the slit. A clear acrylic entrance tube $15 \mathrm{~cm}$ in diameter and $5 \mathrm{~cm}$ in length was attached to the frame providing an entry-way to 
direct fish towards the slit when using a net. An entry tube $\geq 20 \mathrm{~cm}$ long was used with the paddle. The net or paddle was moved at approximately $10 \mathrm{~cm}$ $\mathrm{min}^{-1}$, the speed found by experience to be the highest speed that did not elicit a fast-start, indicative of panic by a fish. Slits were defined as too small to negotiate if fish had not passed through after $5 \mathrm{~min}$ utes. Most fish approached a slit too small to traverse, but backed away.

The paddle and net were equally effective in directing goldfish and angelfish to the slits and gave the same values for minimum slit sizes. Data obtained using the two herding methods were combined. In contrast, the paddle tended to panic silver dollars and data using this method were discarded for the latter species.

Each passage by a fish through a slit, or a failure to pass through after 5 minutes, was one trial. Because fish were neither exhausted nor stressed by a trial, 10 trials were performed at 5 to 15 minute intervals on a given day using each fish with slits of various widths with a given orientation. Additional trials were performed on subsequent days using the same fish until minimum vertical and horizontal slit widths were determined.

The passage of fish through the slits were recorded on video tape. Tape was subsequently analyzed field-by-field (field rate $=60 \mathrm{~Hz}$ ) to determine transit time. This was measured as the time from the entry of the nose into the slit to the exit of the tail. Transit time will be affected by the total length of the fish. Therefore, normalized transit times were calculated for a fish $6 \mathrm{~cm}$ in total length, the approximate average length for the three species tested (Table 1). First the mean speed was calculated from the known length of the fish and observed transit time. Then this speed was used to calculate the time to travel $6 \mathrm{~cm}$.

The ability to traverse slits would be expected to be affected by body size. There is no universal measure of size, and limiting dimensions are unknown for low-speed maneuvers. Common measures of size that may be important are total fish length, maximum body width (occurring at the eyes), span at the pectoral fins, and mass (or volume). At the end of the experiment, fish were anesthetized with 3-aminobenzoic acid ethyl ester (MS-222) and these physical characteristics, plus body depth, were measured (Table 1). Mass was measured to within $1 \mathrm{mg}$. Length, depth, maximum width, and span at the pectoral fins were measured using vernier calipers to within $0.1 \mathrm{~mm}$. Span at the pectoral fins was determined as the sum of the maximum spans of each pectoral fin plus the width of the intervening body.

We calculated minimum relative slit widths by dividing measured minimum slit widths by the various measures of size, thereby providing eight potential measures of maneuverability (two slit orientations and four measures of size). All the measures of size were linear and hence in the same units as slit width with the exception of mass. Mass is numerically equal to volume for these neutrally buoyant fish, when volume ${ }^{1 / 3}$ (numerically mass ${ }^{1 / 3}$ ) can be used to maintain dimensional similarity with slit width. Volume, raised to the appropriate power, is used as a measure of area and length in the evaluation, design and performance of human engineered vehicles (Hoerner 1965), and has been used in studies of animal locomotion (Weihs 1977, 1981,

Table 1. Physical characteristics of three species used to compare maneuverability in traversing slits.

\begin{tabular}{|c|c|c|c|c|}
\hline & units & Goldfish & Silver dollar & Angelfish \\
\hline Total length, TL & $\mathrm{cm}$ & $6.17 \pm 0.56$ & $6.43 \pm 0.65$ & $5.75 \pm 0.34$ \\
\hline Mass, $\mathbf{M}$ & $\mathrm{gm}$ & $2.57 \pm 0.76$ & $4.65 \pm 1.22$ & $2.73 \pm 0.24$ \\
\hline Condition factor, $\mathrm{M} \mathrm{TL}^{-3}$ & & $0.010 \pm 0.001$ & $0.016 \pm 0.0015$ & $0.016 \pm 0.0022$ \\
\hline Maximum body depth & $\mathrm{cm}$ & $1.4 \pm 0.1$ & $3.3 \pm 0.4$ & $2.9 \pm 0.2$ \\
\hline Maximum body + median fin depth & $\mathrm{cm}$ & $2.2 \pm 0.2$ & $4.2 \pm 0.5$ & $5.1 \pm 0.7$ \\
\hline Maximum body width (measured at the eyes) & $\mathrm{cm}$ & $0.71 \pm 0.09$ & $0.83 \pm 0.12$ & $0.68 \pm 0.03$ \\
\hline Span of pectoral fins and intervening body & $\mathrm{cm}$ & $2.69 \pm 0.22$ & $2.57 \pm 0.30$ & $3.10 \pm 0.06$ \\
\hline Sample size & & 10 & 10 & 10 \\
\hline
\end{tabular}




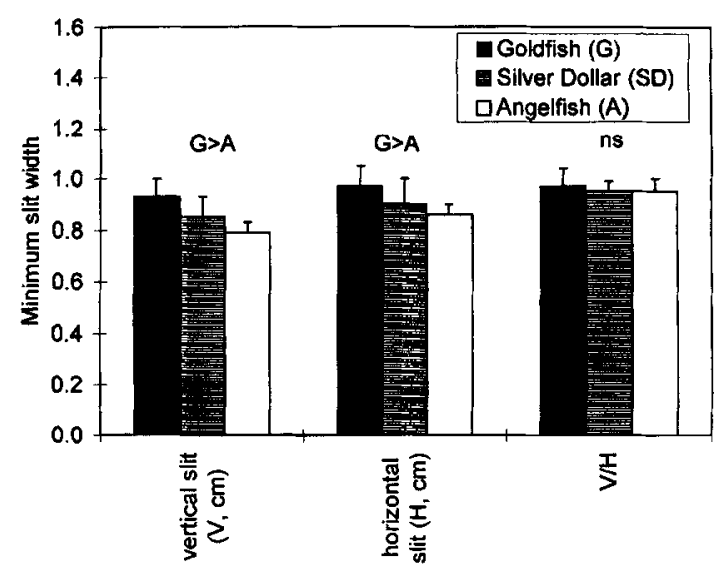

Fig. 2. Minimum vertical, $\mathrm{V}$, and horizontal, $\mathrm{H}$, slit widths negotiated by three species of teleosts, goldfish, G, silver dollars, SD, and angelfish, A, with different body forms. The ratio, $\mathrm{V} / \mathrm{L}$, of minimum vertical to horizontal widths for these data is also shown. Rankings of significant differences are shown as determined in 2-tailed t-tests; the expected ranking is goldfish > silver dollar $>$ angelfish $(\mathrm{G}>\mathrm{SD}>\mathrm{A})$. Vertical bars show $2 \mathrm{SE}$.

Vogel 1994). Less maneuverable fish would be expected to have larger values for minimum relative slit widths for each dimension.

\section{Results}

\section{Fish size}

Size is commonly measured in terms of length and mass (Table 1), which are often linked as condition factor, or mass-length ${ }^{-3}$. Total lengths were similar (t-test; $\mathrm{p}=0.04$ ) for goldfish, silver dollars and angelfish. Goldfish were relatively lighter for their length, with condition factors averaging $0.010 \mathrm{com}$ pared with 0.016 for both silver dollars and angelfish.

Lateral dimensions are most likely to limit ability to negotiate slits (Table 1). Maximum widths measured at the eyes were $0.92 \mathrm{~cm}$ for angelfish, $0.97 \mathrm{~cm}$ for goldfish and $0.95 \mathrm{~cm}$ for silver dollars. These differences were significant only for angelfish compared with silver dollars (t-test, $\mathrm{p}<0.02$ ). The span of the extended pectoral fins was largest for angelfish, averaging $3.1 \mathrm{~cm}$, significantly larger (t-tests, $\mathrm{p}<0.01)$ than goldfish and silver dollars which had

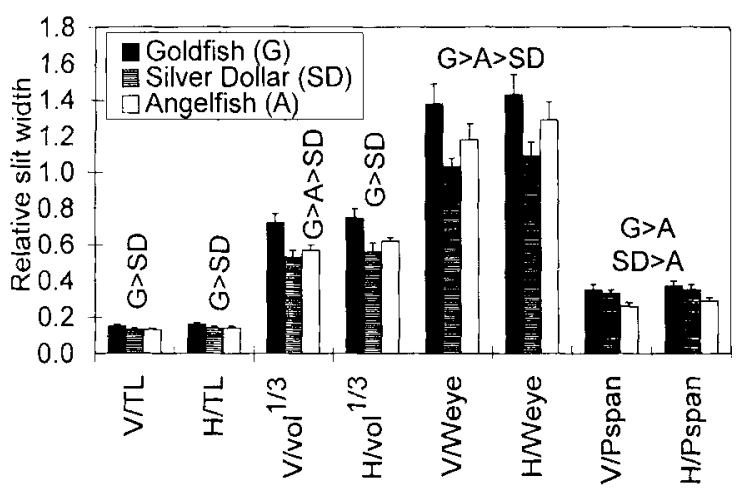

Fig. 3. Summary of minimum relative widths of vertical, V, and horizontal, $\mathrm{H}$, slits negotiated by three species of teleosts. Relative slit widths were obtained by normalizing minimum slit widths by total length, TL, volume ${ }^{1 / 3}$, vol $^{1 / 3}$ (numerically equal to mass ${ }^{1 / 3}$ ), maximum body width measured at the eye, Weye, and the sum of the spans of the pectoral fins and intervening body, Pspan. Rankings of significant differences are shown as determined in 2-tailed $t$-tests; the expected ranking is goldfish $>$ silver dollar $>$ angelfish $(G>S D>A)$. Vertical bars show 2 SE.

similar spans ( $t$-test, $p=0.3$ ) of 2.7 and $2.6 \mathrm{~cm}$ respectively.

\section{Behavior}

Swimming behavior differed among the three species. Goldfish typically swam continuously with numerous turns. This species used body and caudal fin undulation at all times, supplemented by median (dorsal and anal) and paired (pectoral and pelvic) fins working singly or in any combination. Silver dollars usually remained stationary, often behind structures such as the water filter. Angelfish usually hovered and swam short distances in the water column, using small motions of all fins to hold position, but rarely caudal fin undulation. Swimming patterns were not affected by herding, except for silver dollars which were easily panicked by the paddle.

In passing though the partition, fish briefly adducted the paired fins to glide through. They began active swimming after passing through a slit. Fish passed directly through vertical slits, but rotated about the longitudinal (rolling) body axis before passing through horizontal slits. When the width of a horizontal slit was larger than the minimum width 
negotiable, fish swam at an angle to the slit, passing through diagonally. However, fish passed through with the body horizontal when negotiating slits of minimum width.

Caudal fin propulsion is used when fish swim at higher speeds (Webb 1994b), so that goldfish tended to swim at higher routine speeds. As a result, normalized transit times through vertical slits increased in a series of goldfish $<$ silver dollars $<$ angelfish (Fig. 1). Difference were significant for goldfish compared with angelfish and with silver dollars ( $t$-test, $\mathrm{p} \leq 0.05$ ). However, transit times were not ranked in the same way in traversing horizontal slits. Although angelfish still took more time to pass through horizontal slits than goldfish, silver dollars traversed these slits in the least time. Except for goldfish, fish traversed horizontal slits at a higher speed than vertical slits.

\section{Minimum slit widths}

Minimum widths of slits traversed decreased in a series of goldfish $>$ silver dollars $>$ angelfish for both vertical and horizontal orientations (Fig. 2). Differences were significant for goldfish compared with angelfish (t-test, $p \leq 0.01$ ). Minimum slit widths were significantly larger (paired t-tests; $p<0.03$ ) for horizontal slits compared with vertical slits. This presumably reflects the need for the fish to roll and hold the body on its side while passing through horizontal slits.

Absolute differences among species for minimum slit widths traversed were small and may be due to differences in the size of body dimensions. Therefore, relative minimum slit widths were compared among species after dividing absolute minimum slit widths by four measures of body size. Goldfish had the poorest performance for all these measures for both vertical and horizontal slit orientations (Fig. 3). Silver dollars were superior to angelfish in terms of minimum slit widths traversed relative to maximum body width for vertical and horizontal slit orientations, and minimum vertical width relative to volume ${ }^{1 / 3}$. Angelfish were superior to silver dollars for minimum widths of vertical and horizontal slit orientations versus pectoral span.
There were no differences in the performance of angelfish and silver dollars traversing horizontal slits relative to volume ${ }^{1 / 3}$, or horizontal and vertical slits relative to body length.

We also calculated the ratio of the minimum vertical slit width to the minimum width for horizontal slits for each fish. This increased from 0.92 for angelfish through 0.95 for silver dollars to 0.97 for goldfish (Fig. 2). However, differences were not significant (ANOVA, $\mathrm{p}=0.296$ ).

\section{Discussion}

We expected a ranking in terms of minimum relative slit widths negotiated of goldfish $>$ silver dollar $>$ angelfish and a ranking in terms of the ratio of minimum widths for vertical and horizontal slits of angelfish > silver dollar > goldfish, reflecting a ranking of increasing maneuverability. Instead, no consistent patterns were found.

Differences among species in ability to traverse slits will be affected by size. The appropriate measure of size for slow speed maneuvering among obstacles is not known. We normalized minimum slit widths traverse using total length and mass (or volume), the common measures of size used by ichthyologists. Length is most commonly used because of the ease of measurement. Other linear dimensions are often scaled to total length in comparing species (see Webb 1975, Videler 1993). Mass and volume are important because they provide a measure of the amount of material and energy accumulated for future survival (e.g. over-wintering) and reproduction and also the amount of space to accommodate gut volume for digestion, muscle to avoid predators etc. (Webb 1990, 1992, Vogel 1994). Similar criteria (e.g. payload, passenger capacity) are often major criteria in selecting optimal designs for human engineered vehicles (Hoerner 1965, Weihs 1977, 1981). For these reasons, it could be argued that volume measures are the most important metrics for size. Thus another measure of maneuverability is the smallest slit traversed for a given body volume, using volume ${ }^{1 / 3}$ to maintain dimensional similarity.

Using these measures of size to scale minimum 
slit widths traversed, goldfish required larger slits relative to their length and volume ${ }^{1 / 3}$ compared with silver dollars and angelfish. No consistent pattern was found for silver dollars compared with angelfish (Fig. 3).

We also normalized slit widths using maximum body width and pectoral fin span. These represent the minimum and maximum lateral dimensions of the fish in the plane of the slit width which could, therefore, determine minimum widths traversed. In practice, the pectoral fins were furled during the passage itself, but they were used to orient the body and provide the thrust to propel the body through the gap. Bluegill with larger fin spans are more common in weedy habitats (Ehlinger 1990).

Using these measures of lateral size, goldfish again required the largest slit widths. Silver dollars traversed the smallest slits relative to maximum body width, while angelfish traversed the smallest slits relative to pectoral fin span (Fig. 3).

On the basis of eight measures of minimum relative slit widths, goldfish had the poorest maneuverability (Fig. 3). Silver dollars were superior to angelfish for three measures, angelfish were superior to silver dollars in two, and there were no differences for three. These observations suggest that silver dollars and angelfish are approximately equally maneuverable and goldfish are less maneuverable.

However, a different picture emerges when the ability to pass through a horizontal slit is compared with that for a vertical slit. Traversing a horizontal slit requires a fish roll to swim on its side, holding the body in a horizontal posture. Fish with perfect postural control would negotiate vertical and horizontal slits of equal minimum width, when the ratios of minimum slit widths would be unity. Ratios were closer to unity for goldfish, but differences among species were not significantly different.

In view of the large differences in fin and body morphology among these three species, minimum slits widths traversed are remarkably similar. The times to transit slits provided no better indication of definitive advantages accruing to any of the three morphologies studied (Fig. 1). Angelfish took longest time to traverse vertical slits and goldfish the shortest times, associated with the use of low-speed pectoral swimming versus faster caudal fin swim- ming respectively (Videler 1993, Webb 1994b). In this respect, goldfish were more agile in traversing vertical slits, but silver dollars were more agile passing through horizontal slits. At the same time, greater control is presumably needed to swim with the body on its side, when the longer time taken to traverse horizontal slits by angelfish may imply greater control.

The shorter transit times for angelfish and silver dollars traversing horizontal slits compared with vertical slits may appear unexpected in view of the greater challenge of controlling posture while passing through the former. The results probably reflect greater difficulties of controlling posture at low speeds than at higher speeds when propulsive forces are small relative to those required to correct destabilizing perturbations. This point is readily appreciated by any bicycle rider. Thus the ability to swim over a range of low speeds may be an important component affecting ability to negotiate obstacles, for which silver dollars and angelfish appear to have an advantage.

Overall, the results show small differences in the ability of these three species to negotiate slits, but no consistent pattern emerges permitting an unequivocal ranking of performance to correlate with body or fin morphology. At most, a deep body appears to have some advantage over a fusiform body while fin configuration appears unimportant for slow swimming maneuvers. The overwhelming sense of the results is a remarkable similarity among species in spite of the very large differences in body and fin configurations. This appears at variance with natural history observations. These show that fish living in structurally complex habitats are more likely to have fin configurations placing pectoral, anal, dorsal, caudal and usually pelvic propulsors around the center of mass (Moyle \& Cech 1988). As with the design of human-engineered craft maneuvering in low gravity space, this fin organization is presumed to provide thrust forces readily oriented in all directions (Webb 1982a, 1984). Thus chaetodontiform fish are inferred to be more maneuverable because of the complexity of structures characterizing the habitat in which such fish are found.

The discrepancy between the experimental results and expectations from natural history obser- 
vations may reflect assumptions in the experimental design. The usual philosophy used in studying fish locomotion is that functional differences associated with morphological variation will be found at the limits of motor performance. This performance is usually measured in terms of translocation rates (speed and acceleration rate), and maxima are usually induced using threat stimuli (e.g. Beamish 1978, Webb 1986, Eaton et al. 1988, Blaxter \& Fuiman 1990, Gamperl \& Stevens 1991, Domenici \& Blake 1993). The present experiments similarly used a threat stimulus to induce fish to traverse slits. Since all fish experience predation at some point in their lives, perhaps it should not be surprising that they converge in their ability to escape among structures that could provide refuges (Johnson et al. 1988).

While most studies of fish locomotor functionalmorphology have focused on maximizing performance, other studies concerned with energetics consider optimum performance in terms of minimizing costs of transport, maximization of energy acquisition rates, etc. (see Ware 1975, 1978, Kerr 1982, Werner 1986, Weihs \& Webb 1983, Daniel \& Webb 1987, Videler \& Weihs 1982, Videler 1993). Energetically optimal swimming speeds are low compared with maximum possible levels of performance. These low speeds dominate routine activities and energy budgets, as noted in the introduction. Most research on swimming has also emphasized swimming by body and caudal fin undulation, but many fish, including those studied here, make substantial use of their median and paired fins during lowspeed routine activities (Webb 1994b). Therefore, energetic factors may be more important for evaluating performance of various body and fin morphologies used in routine swimming, especially when the paired and non-caudal median fins are the dominant propulsors. Preliminary observations on the same three species tested here suggest they differ in maneuverability during feeding, with the angelfish being more maneuverable and feeding on zooplankton at a higher rate than the other species (Ridley 1994).

We conclude that body form and fin configuration has a remarkably small effect on the ability of fish to traverse slits to escape a threat, but these as- pects of morphology may affect energetics during sub-maximum routine activities.

\section{Acknowledgements}

This work was supported by the National Science Foundation grant number DCB-9017817. Suggestions by two reviewers were gratefully incorporated.

\section{References cited}

Alexander, R. McN. 1967. Functional design in fishes. Hutchinson, London. $160 \mathrm{pp}$.

Beamish, F.W.H. 1978. Swimming capacity. pp. 101-187. In: W.S Hoar \& D.J. Randall (ed.) Fish Physiology, Vol. 7, Locomotion, Academic Press, New York.

Blake, R.W. 1976. On seahorse locomotion. J. Mar. Biol. Ass. UK 56: 939-949.

Blake, R.W. 1977. On ostraciiform locomotion. J. Mar. Biol. Ass, UK 57: 1047-1055.

Blake, R.W. 1978. On balistiform locomotion. J. Mar. Biol. Ass. UK 58: 73-80.

Blake, R.W., L.M. Chatters \& P. Domenici. 1995. Turning radius of yellowfin tuna (Thunnus albacores) in unsteady swimming manoeuvres. J. Fish Biol. 46: 536-538

Blaxter, J.H.S. \& L.A. Fuiman. 1990. The role of the sensory systems of herring larvae in evading predatory fishes. J. Mar. Biol. Ass. UK 70: 413-427.

Boisclair, D. 1992. An evaluation of the stereocinematographic method to estimate fish swimming speed. Can. J. Fish. Aquat. Sci. 49: 523-531.

Boisclair, D. \& M. Tang. 1993. Empirical analysis of the swimming pattern on the net energetic cost of swimming in fishes. $J$. Fish Biol. 42: 169-183.

Breder, C.M. 1926. The locomotion of fishes. Zoologica 4: 159297

Daniel, T.L. \& P.W. Webb. 1987. Physics, design and locomotor performance. pp. 343-369. In: P. Dejours, L. Bolis, C.R. Taylor \& E.R. Weibel (ed.) Comparative Physiology: Life in Water and On Land, Liviana Press, Springer-Verlag, New York.

Domenici, P. \& R.W. Blake. 1993. Escape trajectories in angelfish (Pterophyllum eimekei). J. Exp. Biol. 177: 253-272.

Eaton, R.C., R. DiDomenico \& J. Nissanov. 1988. Flexible body dynamics of the goldfish C-start: implications for reticulospinal command mechanisms. J. Neurosci. 8: 2758-2768.

Ehlinger, T.J. 1990. Habitat choice and phenotype-limited feeding efficiency in bluegill: individual differences and trophic polymorphism. Ecology 71: 886-896.

Ehlinger, T.J. \& D.S. Wilson. 1988. Complex foraging polymor- 
phism in bluegill sunfish. Proc. Nat. Acad. Sci. U.S.A. 85:1878 1882.

Gamperl, A.K. \& E.D. Stevens. 1991. Sprint-training effects on trout (Oncorhynchus mykiss) white muscle structure. Can. J. Zool. 69: 2786-2799.

Howland, H.C. 1974. Optimal strategies for predator avoidance: the relative importance of speed and manoeuverability. J. Theor. Biol. 47: 333-350.

Hoerner, S.F. 1965. Fluid-dynamic drag. Hoerner Fluid Dynamics, Brick Town. pp. 0-1 to Z-8.

Johnson, D.L., R.A. Beamier \& W.E. Lynch. 1988. Selection of habitat structure interstice size by bluegills and largemouth bass in ponds. Trans. Amer. Fish. Soc. 117: 171-179.

Kerr, S.R. 1982. Estimating the energy budgets of actively predatory fishes. Can. J. Fish. Aquat. Sci. 39: 371-379.

Krohn, M.M. \& D. Boisclair. 1994. Use of a stereo-video system to estimate the energy expenditure of free-swimming fish. Can. J. Fish. Aquat. Sci. 51: 1119-1127.

Moyle, P.B. \& J.J. Cech, 1988. Fishes: an introduction to ichthyology. Prentice Hall, Englewood Cliffs. 559 pp.

Nilsson, G.E., P. Rosén \& D. Johansson. 1993. Anoxic depression of spontaneous locomotion activity in crucian carp quantified by a computerized imaging technique. J. Exp. Biol. 180: 153162.

Norberg, U.M. 1990. Vertebrate flight. Springer-Verlag, New York. $291 \mathrm{pp}$.

Videler, J.J. 1993. Fish swimming. Chapman and Hall, New York. $260 \mathrm{pp}$.

Videler, J.J. \& D. Weihs. 1982. Energetic advantages of burstand-coast swimming of a fish at high speeds. J. Exp. Biol. 97: 169-178.

Vogel, S. 1994. Life in moving fluids. Princeton University Press, Princeton. $467 \mathrm{pp}$.

Ware, D.M. 1975. Growth, metabolism, and optimal swimming speed of a pelagic fish. J. Fish. Res. Board Can. 32: 33-41.

Ware, D.M. 1978. Bioenergetics of pelagic fish: theoretical changes in swimming speed in relation with body size. J. Fish. Res. Board Can. 35: 220-228.

Webb, P.W. 1975. Hydrodynamics and energetics of fish population. Bull. Fish. Res. Board Canada 190: 1-159.

Webb, P.W. 1976. The effect of size on the fast-start performance of rainbow trout (Salmo gairdneri Richardson) and a consideration of piscivorous predator-prey interactions. J. Exp. Biol. 65: $157-177$.

Webb, P.W. 1982. Locomotor patterns in the evolution of actinopterygian fishes. Amer. Zool. 22: 329-342.

Webb, P.W. 1983. Speed, acceleration and manoeuverability of two teleost fishes. J. Exp. Biol. 102: 115-122.

Webb, P.W. 1984. Body form, locomotion and foraging in aquatic vertebrates. Amer. Zool. 24: 107-120.

Webb, P.W. 1986. Locomotion and predator-prey relationships. pp. 24-41. In: M.E. Feder \& G.V. Lauder (ed.) Predator-Prey Relationships, Chicago University Press, Chicago.

Webb, P.W. 1990. How does benthic living affect body volume, tissue composition, and density of fishes? Can. J. Zool. 68: 1250-1255.

Webb, P.W. 1991. Composition and mechanics of routine swimming of rainbow trout, Oncorhynchus nerka. Can. J. Fish. Aquat. Sci. 48: 583-590.

Webb, P.W. 1992. Is the high cost of body/caudal fin undulatory propulsion due to increased friction drag? J. Exp. Biol. 162: 157-166.

Webb, P.W. 1994a. Exercise performance of fish. pp. 1-49. In: J.H. Jones (ed.) Advances in Veterinary Science and Comparative Medicine 38b, Academic Press, Orlando.

Webb, P.W. 1994b. The biology of fish swimming. pp. 45-62. In: L. Maddock, Q. Bone \& J.V. Rayner (ed.) Mechanics and Physiology of Animal Swimming, Cambridge University Press, Cambridge.

Webb, P.W. \& R.S. Keyes. 1981. Division of labor between median fins in swimming dolphin fish. Copeia 1981: 901-904.

Weihs, D. 1977. Effects of size on sustained swimming speeds of aquatic organisms. pp. 333-338. In: T.J. Pedley (ed.) Scale Effects in Animal Locomotion, Academic Press, New York.

Weihs, D. 1981. Effect of swimming path curvature on the energetics of fish. U.S. Fish. Bull. 79: 171-176.

Weihs, D. \& P.W. Webb. 1983. Optimization of locomotion. pp. 339-371. In: P.W. Webb \& D. Weihs (ed.) Fish Biomechanics, Praeger, New York.

Werner, E.E. 1986. Species interactions in freshwater fish communities. pp. 344-357. In: J. Diamond \& T.J. Case (ed.) Community Ecology, Harper \& Row, New York. 